\title{
PERKEMBANGAN AWAL LARVA KERAPU KERTANG (Epinephelus lanceolatus)
}

\author{
Philip Teguh Imanto") dan Made Suastika*)
}

\begin{abstract}
ABSTRAK
Observasi pada larva kerapu kertang (E. lanceolatus) dilaksanakan di Balai Besar Riset Perikanan Budidaya Laut (BBRPBL), Gondol-Bali, untuk mengumpulkan informasi dasar tentang perkembangan awal morfologi larva yang penting untuk menunjang keberhasilan pembenihannya. Larva berasal dari telur hasil pemijahan yang dirangsang dengan hormon (di Taiwan) dan ditransportasikan segera setelah menetas (D-0) melalui transportasi udara ke laboratotium pembenihan BBRPBL, Gondol. Pengamatan dilakukan dengan memanfaatkan fasilitas tangki $500 \mathrm{~L}$ dengan sistem air resirkulasi. Dari data yang dihimpun diketahui bahwa rata-rata panjang total larva (D-1) 2,48 mm; D-8 3,17 $\mathrm{mm}$; dan tumbuh dengan cepat mencapai $10,79 \mathrm{~mm}$ pada D-19. Kuning telur larva yang berumur sehari (D-1) rata-rata bervolume $150,3 \times 10^{-4} \mathrm{~mm}^{3}$ dan pada hari ketiga terserap $42,61 \%$ dan habis pada hari keempat (D-4). Butir minyak larva D-1 sebesar $41,9 \times 10^{-4} \mathrm{~mm}^{3}$ dan masih tersisa sebesar $0,34 \times 10^{-4} \mathrm{~mm}^{3}$ sampai dengan D-6. Mulut larva diperhitungkan sudah mencapai lebar sebesar $200 \mu \mathrm{m}$ pada D-2. dan mampu untuk memangsa rotifer sejalan dengan pigmentasi mata yang mulai terjadi pada D-2 dan sempurna pada D-3. Dari analisis pertumbuhan terjadi titik belok (flexion point) pada D-8 dan setelah itu terjadi kurva pertumbuhan yang cepat $y=0,6747 x-2,5508$. Berdasarkan hasil observasi tersebut maka pemberian pakan awal untuk larva kerapu kertang sudah bisa diberikan pada D-2 akhir (sore), pada D-8 komposisi pakan alami sudah harus diubah dengan memberikan pakan yang lebih besar dan bernutrisi tinggi.
\end{abstract}

ABSTRACT: Larval life development of the king grouper (E. lanceolatus). By: Philip Teguh Imanto and Made Suastika

Observation on early development of E. lanceolatus larvae have been conducted in laboratory condition at Gondol Research Institute for Mariculture (GRIM) Bali; the purpose was to gain basic data mainly on the larval development stage to support both larval rearing and aquaculture technique of this species. The larvae from egg were produced by induced spawning technique and transported on D-O to GRIM. Observation have been conducted in $500 \mathrm{~L}$ tank with recirculation (close system) facilities. Morphological data showed that the total length of larvae on D-1 was 2.48 $\mathrm{mm}$, became $3.17 \mathrm{~mm}$ on $D-8$ and grew faster to reach $10.75 \mathrm{~mm}$ on $D-19$. The volume of yolk on D-1 was $150.3 \times 10^{-4} \mathrm{~mm}^{3}$ and was absorbed $42,61 \%$ on D-3 and finished on $D-4$. Oil globule on D-1 was $41.9 \times 10^{-4} \mathrm{~mm}^{3}$ and still remained $0.34 \times 10^{-4} \mathrm{~mm}^{3}$ on D-6. The mouth width of larval was $200 \mu \mathrm{m}$ on D-2 and able to catch and feed rotifer in line with eye pigmentation where started from D-2 (in the afternoon) and became completed on D-3 early morning. The flexion point was on D-8 with faster growth with curve at $y=0.6747 x-2.5508$ afterward. Based on this result, there are some key points, first feeding for king grouper larvae might start on late D-2, and on D-8 larval feed should be changed with bigger size and more nutritious feed.

KEYWORDS: king grouper, E. lanceolatus, larval development, larval rearing, eye pigmentation

*) Peneliti pada Balai Besar Riset Perikanan Budidaya Laut, Gondol 


\section{PENDAHULUAN}

Kerapu kertang (Epinephelus lanceolatus) atau sering juga disebut kerapu naga (king grouper) merupakan salah satu jenis kerapu yang memiliki keunggulam dengan ukurannya yang besar (sampai di atas $90 \mathrm{~kg}$ ) dengan pertumbuhan yang cepat serta nilai pasar yang cukup tinggi. Penyebaran kerapu kertang cukup luas meliputi seluruh perairan IndoPasifik Barat maupun sepanjang perairan dengan kondisi tropis. Sementara ikan yang diperdagangkan berasal dari upaya penangkapan dan sebagian dari hasil budi daya yang menggunakan benih impor.

Untuk membatasi kegiatan penangkapan yang berlebihan maka usaha budi daya perlu dikembangkan yang harus didukung dengan pasok benih produksi dalam negeri. Penyediaan benih yang memadai merupakan salah satu permasalahan yang sangat mendesak untuk dicarikan pemecahannya (Imanto \& Basyarie, 1993). Kegiatan pembenihan kerapu telah berhasil dengan kerapu tikus, Cromileptes altivelis (Tridjoko et al., 1996; 1999), kerapu macan, Epinephelus fuscoguttatus (Kohno et al., 1990; Mayunar et al., 1991; Muchari et al., 1991), kerapu batik, E. microdon (Slamet \& Tridjoko, 1997), kerapu sunu, Plectropoma spp. (Suastika \& Imanto, 2006), kerapu Lumpur, E. coioides (Priyono \& Setiadharma, 2003) serta kerapu pasir (Slamet \&S. Ismi, 2006).

Penelitian ini bertujuan untuk mengetahui perkembangan awal morfologi larva kerapu kertang (E. lanceolatus), utamanya untuk mengetahui perkembangan morfologi stadia larva. Penggalian informasi dan data dasar ini diharapkan dapat menunjang keberhasilan pembenihan dan budi dayanya yang saat ini tengah dirintis.

\section{BAHAN DAN METODE}

Larva yang digunakan untuk pengamatan berasal dari telur hasil pemijahan yang dirangsang dengan hormon dan setelah menetas (D-0) di pembenihan ikan laut di Taiwan (swasta) segera ditransportasikan lewat pesawat udara dan transportasi darat ke laboratorium pembenihan ikan laut di Balai Besar Riset Perikanan Budidaya Laut, Gondol, Bali.

Pemeliharaan larva ikan untuk kegiatan observasi ini menggunakan tangki volume 500 liter dengan sistem resirkulasi dilengkapi dengan aerasi. Media pemeliharaan adalah air laut dengan salinitas $34 \mathrm{ppt}$ dengan kondisi suhu air berkisar antara $27^{\circ} \mathrm{C}-28^{\circ} \mathrm{C}$.

Pengamatan morfologi larva dimulai pada saat larva sampai di laboratorium (D-1) dan dilanjutkan setiap hari pada pukul 10.00 WITA sampai dengan D-10 dan dilanjutkan setelah berumur D-17 sampai D-19. Contoh larva diambil dengan menggunakan pipa kaca $5 \mathrm{~mm}$ dan kemudian ditempatkan pada single concave object glass. Pengamatan dilakukan dengan stereoskopis mikroskop Olympus yang telah dilengkapi dengan micrometer, jumlah sampel pada setiap waktu pengamatan adalah enam ekor larva.

Peubah yang diamati meliputi panjang total larva, ukuran kuning telur (yolk), dan butir minyak (oil globule) serta ukuran lebar mulut. Volume kuning telur dan butir minyak dihitung dengan rumus sesuai metode Blaxter \& Hempel (1963) dalam Kohno et al. (1986). Hasil perhitungan merupakan nilai rata-rata dari seluruh sampel yang diamati. Selain itu, dicatat pula waktu terjadinya pigmentasi mata dan bukaan mulut.

\section{HASIL DAN BAHASAN}

\section{Perkembangan Morfologi}

Larva kerapu kertang yang sampai di laboratorium sudah berumur 1 hari (D-1) yang berukuran panjang total rata-rata 2,48 $\pm 0,04$ $\mathrm{mm}$ yang relatif lebih besar dibandingkan dengan larva ikan kakap merah (Lutjanus argentimaculatus) hasil pengamatan di Gondol berkisar antara 2,17-2,44 mm (Imanto et al., 2001 b). Bila dibandingkan dengan larva kerapu lain, ukuran larva kerapu kertang juga relatif lebih besar dibanding dengan kerapu bebek, Cromileptes altivelis di mana larva yang baru menetas berukuran 1,74 mm (Tridjoko et al., 1996), larva kerapu batik, Epinephelus microdon 1,52 $\pm 0,15 \mathrm{~mm}$ (Slamet \& Tridjoko, 1997) dan pada larva kerapu macan, E. fuscoguttatus 1,34 $\pm 0,053 \mathrm{~mm}$ (Kohno et al., 1990).

Pertumbuhan larva mengalami peningkatan sangat cepat setelah berumur 8 hari dengan ukuran panjang total larva 4,03 $\pm 0,31 \mathrm{~mm}$. yang menjadi 10,79 $\pm 0,11 \mathrm{~mm}$ dalam 11 hari (D-19) (Gambar 1), yang diduga berkaitan dengan berubahnya pola memilih pakan sesuai perkembangan organ pemangsaan dengan lebar mulut mendekati $700 \mu \mathrm{m}$ pada umur tersebut. 


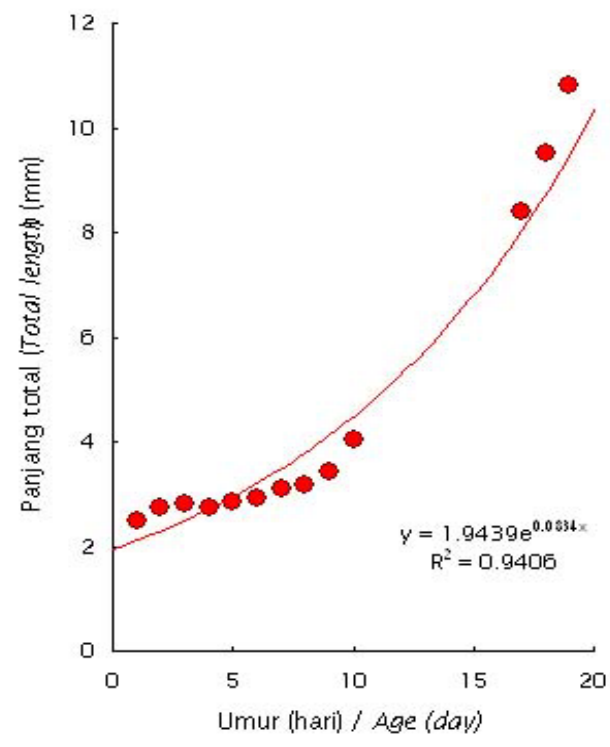

Gambar 1. Pertumbuhan panjang total larva kerapu kertang, E.lanceolatus

Figure 1. Length development of king grouper larvae, E.lanceolatus

Untuk mengetahui titik belok pertumbuhannya yang tepat dicoba untuk melakukan analisis regresi dari 2 garis pertumbuhan larva kerapu kertang dengan koefisien korelasi tertinggi yang disajikan pada Tabel 1 , sehingga diketahui titik potong/pertemuan dari dua garis regresi linear tersebut berada pada saat larva berumur 8,6 hari dan titik belok pertumbuhannya (flexion point) disajikan pada Gambar 2. Hal ini menunjukkan bahwa pertumbuhan larva berlangsung lambat sebelum umur 8,6 hari dan tumbuh lebih cepat sesudahnya.

\section{Energi Endogenus}

Larva kerapu kertang E. lanceolatus pada umur D-1 memiliki kuning telur (yolk) dengan volume $150,3 \times 10^{-4} \mathrm{~mm}^{3}$, sedang butir minyak (oil globulle) 41,9 × 10-4 $\mathrm{mm}^{3}$. Keragaan energi endogenous pada kuning telur dari larva kerapu kertang tergolong paling kecil dibanding ikan laut lainnya, sedang butir minyak relatif lebih besar. Larva kakap merah (L. argentimaculatus) yang baru menetas membawa kuning telur dengan ukuran berkisar antara 1.489 hingga $1.817 \times 10^{-4} \mathrm{~mm}^{3}$, sedangkan butir minyaknya antara 20,2 hingga $24,7 \times 10^{-4} \mathrm{~mm}^{3}$ (Doi \& Singhagraiwan, 1993). Larva kerapu macan membawa kuning telur dengan volume $1.687,3 \times 10^{-4} \mathrm{~mm}^{3}$ dan butir minyak sebesar $35,7 \times 10^{-4} \mathrm{~mm}^{3}$ (Kohno et al., 1990), sedangkan larva kerapu bebek membawa $3.106 \times 10^{-4} \mathrm{~mm}^{3}$ kuning telur dan $48,4 \times 10^{-4} \mathrm{~mm}^{3}$ butir minyak (Tridjoko et al., 1999). Larva ikan beronang (Siganus javus) mempunyai volume kuning telur sebesar 86,9 $\times 10^{-4} \mathrm{~mm}^{3}$ sedangkan butir minyaknya sebesar $29,0 \times 10^{-4} \mathrm{~mm}^{3}$ (Diani et al., 1990). Larva kerapu batik membawa kuning telur dengan ukuran panjang $843 \pm 35,1 \mu \mathrm{m}$ dan tinggi 780 $\pm 32,5 \mu \mathrm{m}$. dengan butir minyak berdiameter $176 \pm$ 5,29 $\mu \mathrm{m}$ (Slamet \& Tridjoko, 1997).

Aktivitas penyerapan kuning telur larva kerapu kertang E. lanceolatus berlangsung cepat, tercatat $42,61 \%$ pada D-3. Dengan volume kuning telur masih sebesar 86,2 x 10-4 $\mathrm{mm}^{3}$ (Gambar 3) yang habis terserap semuanya pada D-4. Keragaan yang agak lain adalah pada proses penyerapan butir minyak berlangsung cukup cepat pada 3 hari pertama yang mencapai persentase penyerapan $91,48 \%$ dan setelah itu lambat dan bertahan hingga habis 
Tabel 1. Analisis regresi garis pertumbuhan larva kerapu kertang (E. lanceolatus). Persamaan garis adalah $T L=\boldsymbol{a}$ (umur larva) $+\boldsymbol{b}$; $r$ : koefisien korelasi

Table 1. Regresion analysis for the growth of king grouper larvae $E$. lanceolatus. The line equation is $T L=a($ larval age $)+\boldsymbol{b} ; \boldsymbol{r}$ : koefisien korelasi

\begin{tabular}{|c|c|c|c|c|c|}
\hline $\begin{array}{c}\text { Umur larva } \\
\text { (hari) } \\
\text { Age of larvae } \\
\text { (day) }\end{array}$ & $\mathbf{n}$ & a & b & $r$ & $\begin{array}{l}\text { Titik belok } \\
\text { pert umbuhan } \\
\text { Umur (hari) } \\
\text { Flexion point } \\
\text { Age (days) }\end{array}$ \\
\hline D1 - 9 & 9 & 0.0757 & 25.949 & 0,8631 & \multirow[t]{2}{*}{8,6} \\
\hline D8 -19 & 6 & 0.6747 & $-2,5508$ & 0,9980 & \\
\hline
\end{tabular}

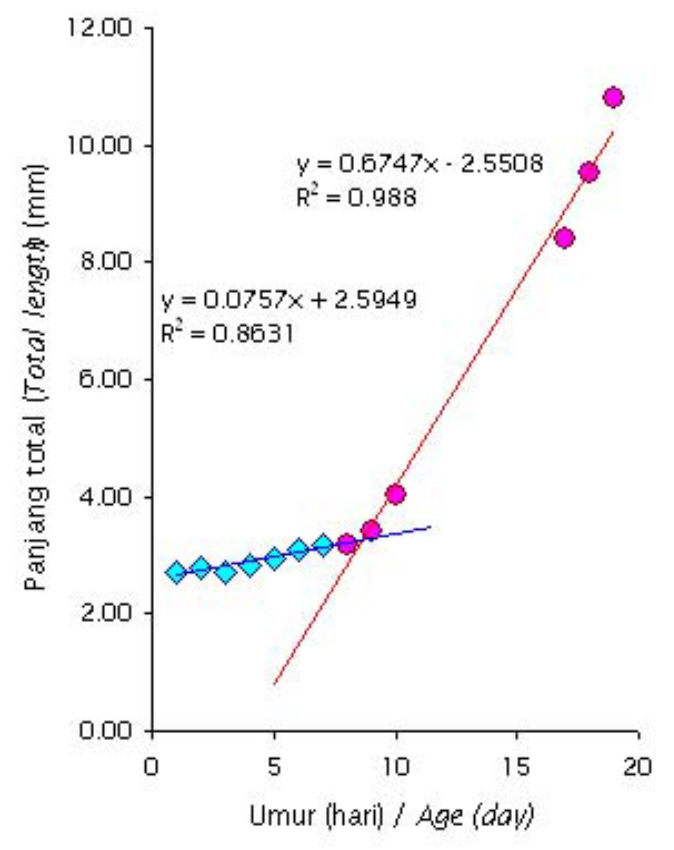

Gambar 2. Titik belok pertumbuhan larva kerapu kertang, E. lanceolatus

Figure 2. Flexion point of larval king grouper, E. Ianceolatus

sempurna pada hari ke-7 (D-7). Keragaan pemanfaatan endogenous larva kerapu kertang berbeda dengan larva kerapu macan (E. fuscoguttatus) dengan penyerapan $90 \%$ kuning telur terjadi pada 24 jam setelah menetas, sedangkan penyerapan butir minyaknya berjalan lebih lambat (Kohno et al., 1990). Pada larva ikan napoleon (Cheilinus undulatus), penyerapan kuning telur berlangsung cepat selama $30-40$ jam setelah menetas, sedangkan pada waktu yang sama penyerapan butir minyaknya berlangsung lebih lambat dan berangsur meningkat pada 36 hingga 68 jam setelah menetas (Imanto et al., 2001a). 


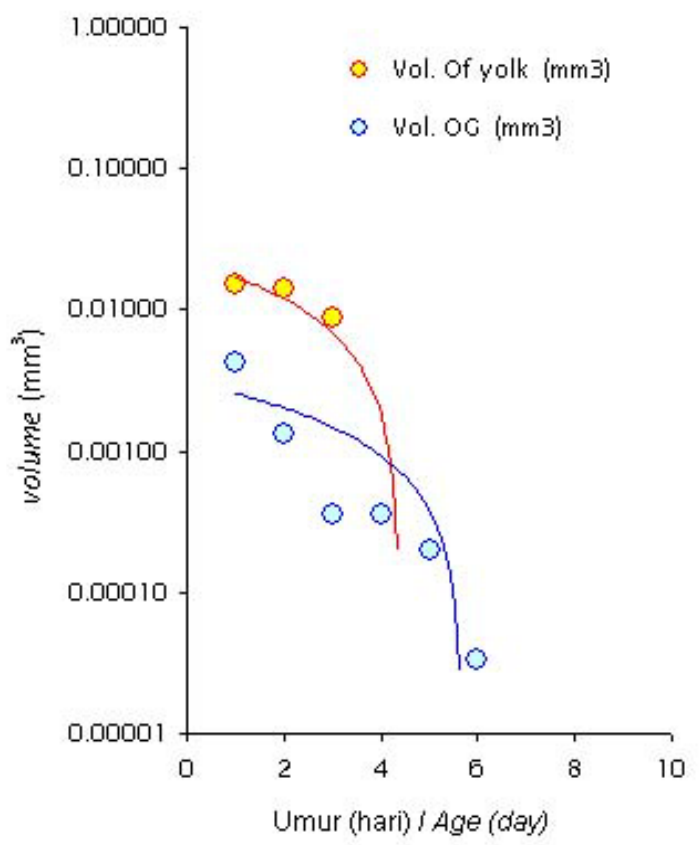

Gambar 3. Penyerapan energi endogenous larva kerapu kertang, E. lanceolatus

Figure 3. Endogenous energy absortion of king grouper larvae, E. lanceolatus

\section{Organ Pemangsaan}

Organ pemangsaan yang terpenting pada awal kehidupan larva adalah mata dan mulut yang berfungsi untuk melihat mangsa, mengukur dan menelannya. Pigmentasi mata tercatat mulai berkembang pada D-2 sore hari dan sempurna pada D-3 pagi hari, yang mengindikasikan bahwa larva sudah siap melakukan pencarian mangsa.

Dari catatan lebar mulut larva didapatkan garis regresi eksponensial dengan persamaan $y=0.1522 \mathrm{e}^{0.1304 x}$ (Gambar 4), yang dikalkulasikan memiliki ukuran $200 \mu \mathrm{m}$ pada umur D-2, ukuran ini relatif lebih besar dari lebar mulut larva kerapu bebek yang mulai membuka dengan 120 um (Tridjoko et al., 1999) maupun larva L. argentimaculatus dengan ukuran mulut (mouth size) sekitar $145 \mu \mathrm{m}$. (Doi \& Kohno, 1985 dalam Doi \& Singhagraiawan, 1993).

Dari Gambar 3 dan 4 diketahui bahwa periode D-3-4 setelah menetas merupakan masa yang penting bagi larva karena pada kisaran waktu tersebut cadangan makanan di dalam (endogenous energy) terserap cepat, pigmentasi mata telah sempurna, dan mulut telah membuka, di mana kelengkapan morfologis tersebut menunjukkan bahwa pada saat itu larva telah siap untuk mencari dan menangkap makanan dari luar tubuhnya. Dengan kata lain, periode waktu tersebut merupakan periode kritis dalam stadia larva karena merupakan masa transisi dari pemanfaatan endogenous energy (kuning telur dan butir minyak) ke exogenous energy yang berasal dari pemanfaatan pakan alami (zooplankton). Ketersediaan jenis pakan alami yang sesuai dengan ukuran lebar mulut larva dalam jumlah yang memadai pada periode waktu tersebut merupakan syarat mutlak yang harus terpenuhi untuk menjamin sintasan larva selanjutnya.

Pengamatan morfologis larva kerapu kertang (E. lanceolatus) memberikan gambaran tentang ukuran sediaan pakan serta skema pengelolaan pemberian pakan. Dari Gambar 4 diketahui dengan perhitungan garis regresi eksponensial lebar mulut larva pada D-2 sebesar $200 \mu \mathrm{m}$, yang berarti cukup dengan 


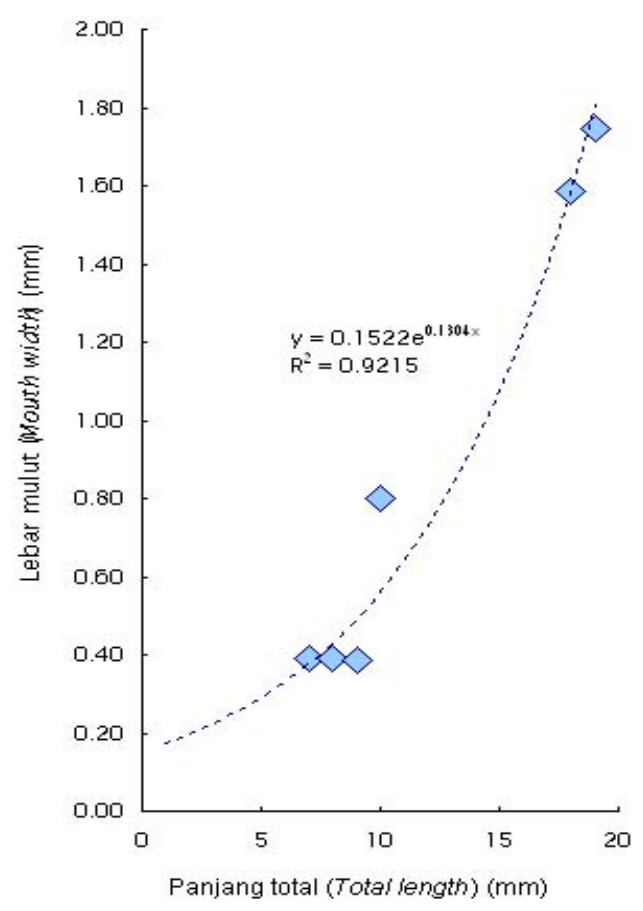

Gambar 4. Perkembangan lebar mulut larva kerapu kertang, E. lanceolatus

Figure 4. Mouth width development of king grouper larvae, E. Ianceolatus

sediaan rotifer tipe $S$ atau lebih besar. Dan memperhatikan Gambar 4 nampak jelas adanya titik belok pertumbuhan (flexion point) setelah hari kedelapan. Perubahan garis pertumbuhan tersebut juga sekaligus mengindikasikan adanya kebutuhan nutrisi yang bertambah untuk menunjang pertumbuhan yang optimal, serta penjadwalan sediaan pakan yang berubah.

Perkembangan morfologis larva (larval development pattern) sangat menentukan dalam penyusunan pola manajemen pemeliharaan larva dengan tepat, data yang berhasil dihimpun dari larva kerapu kertang ( $E$. lanceolatus) dituangkan pada Gambar 5. Dari gambar ini terlihat kaitan antara pertumbuhan panjang total larva kerapu kertang, keberadaan energi endogenous dalam bentuk cadangan kuning telur dan butir minyak, pigmentasi mata, dan perkembangan lebar mulutnya yang berguna dalam penyusunan strategi sediaan pakannya.

\section{KESIMPULAN DAN SARAN}

- Pertumbuhan larva kerapu kertang E. lanceolatus meningkat dengan cepat setelah D-8 hal ini diduga kuat berkaitan erat dengan perubahan pola pemangsaan yang berkaitan dengan organ pemangsaan yaitu mata dan mulut.

- Pigmentasi mata larva terbentuk secara sempurna bersamaan dengan mulut yang aktif dengan ukuran lebar mulut di atas 200 $\mu \mathrm{m}$ pada $\mathrm{D}-3$.

- Periode kritis stadia larva terjadi pada D-3-4 karena bila sediaan makanan (exogenous energy) awal gagal pada periode tersebut akan terjadi kekurangan nutrisi/energi karena sumber nutrisi dari endogenous energy habis pada D-4.

- Pakan alami yang diberikan sebagai sumber exogenous energy pada awal pemangsaan larva kerapu kertang E. lanceolatus disesuaikan dengan ukuran lebar mulutnya 


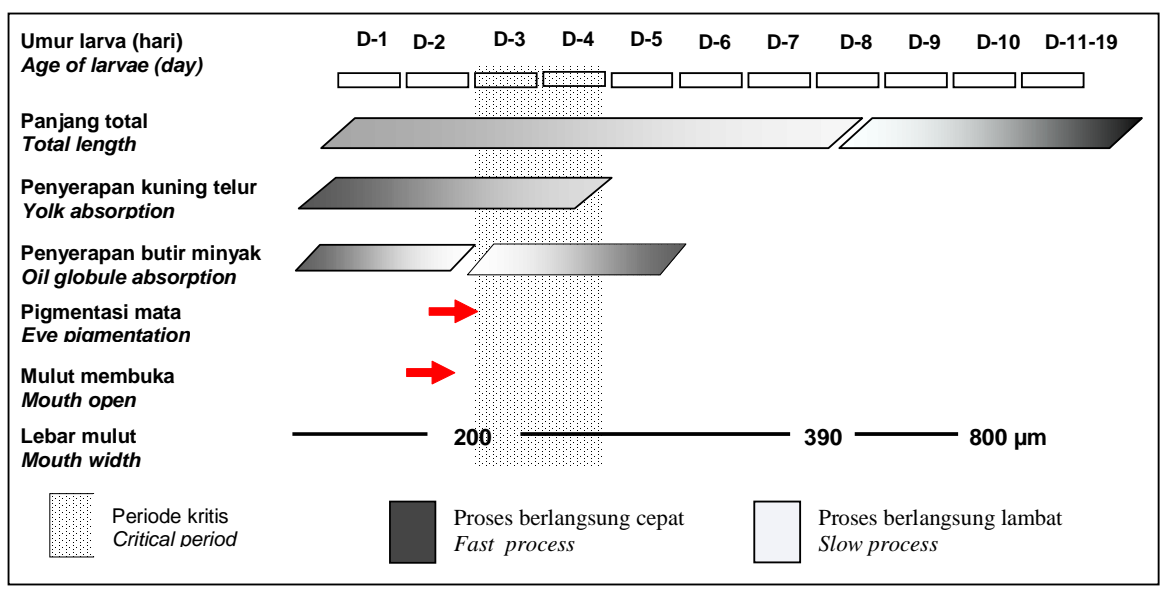

Gambar 5. Beberapa parameter perkembangan morfologi larva kerapu kertang, E. lanceolatus

Figure 5. Some parameters of morphological development of king grouper larvae, $E$. lanceolatus

yang berukuran di atas $200 \mu \mathrm{m}$. Pemilihan sediaan jasad pakan tidak terlalu menjadi masalah pada pemeliharaan larva kerapu kertang E. lanceolatus, bisa dengan rotifer tipe $S$ maupun copepodite.

\section{DAFTAR PUSTAKA}

Diani, S., B. Slamet, P.T. Imanto, and H. Kohno. 1990. Resorption of endogenous nutrition and initial feeding of the rabbitfish, Siganus javus. Bull. Pen. Perikanan. Special Edition. $1: 83-88$.

Doi, M. and Singhagraiwan. 1993. Biology and culture of the red snapper, Lutjanus argentimaculatus. The Research Project of Fishery Resource Development in The Kingdom of Thailand. The Eastern marine fisheries development center (EMDEC), Department of Fisheries, Ministry of Agriculture and Cooperatives, Thailand. 51 pp.

Imanto, P.T. dan A. Basyarie. 1993. Budidaya ikan laut, pengembangan dan permasalahannya. Prosiding Rapat Teknis Penelitian Perikanan Budidaya Pantai di Tanjung Pinang. 10: 93-106.

Imanto, P.T., R. Melianawati, dan B. Slamet. 2001a. Pola penyerapan nutrisi endogenous pada stadia awal larva ikan napoleon (Cheilinus undulatus). Makalah disampaikan pada Seminar Laut Nasional III, 29-31 Mei 2001 di Jakarta. 7 pp.

Imanto, P.T., R. Melianawati, M. Suastika, dan J.H. Hutapea. 2001 b. Pola pemangsaan larva ikan kakap merah (Lutjanus sp.) menunjang managemen pemeliharaan larva. Laporan Teknis Proyek Inventarisasi dan Evaluasi. Balai Besar Riset Perikanan Budidaya Laut Gondol. 18 pp.

Kohno, H., S. Hara, and Y. Taki. 1986. Early larval development of the seabass Lates calcarifer with emphasis on the transition of energy sources. Bull. of the Japanese Soc. of Sci. Fish. 52(10): 1,719-1,725.

Kohno, H., S. Diani, P. Sunyoto, B. Slamet, and P.T. Imanto. 1990. Early development events associated with changeover of nutrient sources in the grouper, Epinephelus fuscoguttatus, larvae. Bull. Pen. Perikanan, special edition. 1: 51-64.

Mayunar, P.T. Imanto, S. Diani, dan T. Yokokawa. 1991. Pemijahan ikan kerapu macan, Epinephelus fuscoguttatus. Bull. Pen. Perikanan. Special Edition. 2: 15-22.

Muchari, A. Supriatna, R. Purba, T. Ahmad, dan H. Kohno. 1991. Pemeliharaan larva kerapu macan, Epinephelus fuscoguttatus. Bull. Pen. Perikanan. Special Edition. 2: 43-52.

Priyono, A. dan T. Setiadharma, 2003. Pematangan dan pemijahan induk kerapu lumpur dengan chronik hormone LHRH-a dan 17 á-MT. Laporan Penelitian, TA.2002. Balai Besar Riset Perikanan Budidaya Laut, Gondol. p. 256-269.

Slamet, B. dan S. Ismi. 2006. Pemeliharaan dan pemijahan ikan kerapu pasir (Epinephelus corallicola). Makalah pada Seminar 
Nasional Perikanan dan Temu Bisnis Kerapu. Denpasar. 12 pp.

Slamet, B. dan Tridjoko. 1997. Pengamatan pemijahan alami, perkembangan embrio dan larva ikan kerapu batik, Epinephelus microdon dalam bak terkontrol. J. Pen. Per. Indonesia. III(4): 40-50.

Suastika, M. dan P.T. Imanto. 2006. Studi awal pada keragaan pemijahan induk kerapu sunu (Plectropomus sp.) perkembangan embrio dan penetasan. Makalah pada Seminar Nasional Perikanan danTemu Bisnis Kerapu, Denpasar. 11 pp.

Tridjoko, B. Slamet, D. Makatutu, dan K. Sugama. 1996. Pengamatan pemijahan dan perkembangan telur ikan kerapu bebek, Cromileptes altivelis pada bak secara terkontrol. J. Pen. Per. Indonesia. 2(2): 5562.

Tridjoko, B. Slamet, T. Aslianti, Wardoyo, S. Ismi, J.H. Hutapea, K.M. Setiawati, I. Rusdi, D. Makatutu, A. Prijono, T. Setiadharma, M. Hirokazu, and K. Shigeru. 1999. Research and Development: The Seed Production Technique of Humpback Grouper, Cromileptes altivelis. JICA and Gondol Research Station for Coastal Fisheries. 54 pp. 